\title{
Conservative Treatment of Severe Tracheal Laceration After Endotracheal Intubation
}

\author{
Cheng-Yu Chang MD, Shih-Lung Cheng MD PhD, and Shih-Chieh Chang MD
}

\begin{abstract}
Endotracheal intubation can lead to iatrogenic trauma to the upper airways. Superficial mucosal tears in the mouth, pharynx, or larynx are common and can cause secondary infection and acute respiratory distress due to massive air leak. We report a patient who sustained a severe 5-cm tracheal laceration and subcutaneous emphysema after intubation. She was successfully weaned from the ventilator after adjustment of the endotracheal cuff, therapy with broad-spectrum antibiotics, and continuous airway humidification. Key words: endotracheal intubation; tracheal laceration; subcutaneous emphysema. [Respir Care 2011;56(6):861-862. (C) 2011 Daedalus Enterprises]
\end{abstract}

\section{Introduction}

Endotracheal intubation can cause iatrogenic trauma to the upper airways. Subcutaneous emphysema after tracheal laceration is a rare but potentially serious complication. Early bronchoscopy is essential to confirm the diagnosis and to assess the extent of injury. Early surgical repair is the preferred treatment for most patients with large lacerations, but conservative treatment may be a viable alternative for patients with small lacerations and those judged unsuitable for surgery.

\section{Case Report}

A 68-year-old woman with a history of hypertension, diabetes mellitus, congestive heart failure, and end-stage renal disease had been undergoing hemodialysis regularly for 2 years. She complained of exertional dyspnea and watery diarrhea for 3 days. We noted a decreased level of consciousness in the emergency department. Chest radiograph (Fig. 1)

Drs Cheng-Yu Chang and Shih-Lung Cheng are affiliated with the Department of Chest Medicine, Far Eastern Memorial Hospital, Taipei, Taiwan. Dr Shih-Chieh Chang is affiliated with the Department of Internal Medicine, National Yang-Ming University Hospital, Yilan, Taiwan.

The authors have disclosed no conflicts of interest.

Correspondence: Shih-Chieh Chang, Department of Internal Medicine, National Yang-Ming University Hospital, No. 152 Xin-Min Road, Yilan City 260 Taiwan. E-mail: dtsurga9@yahoo.com.tw.

DOI: $10.4187 /$ respcare.00891

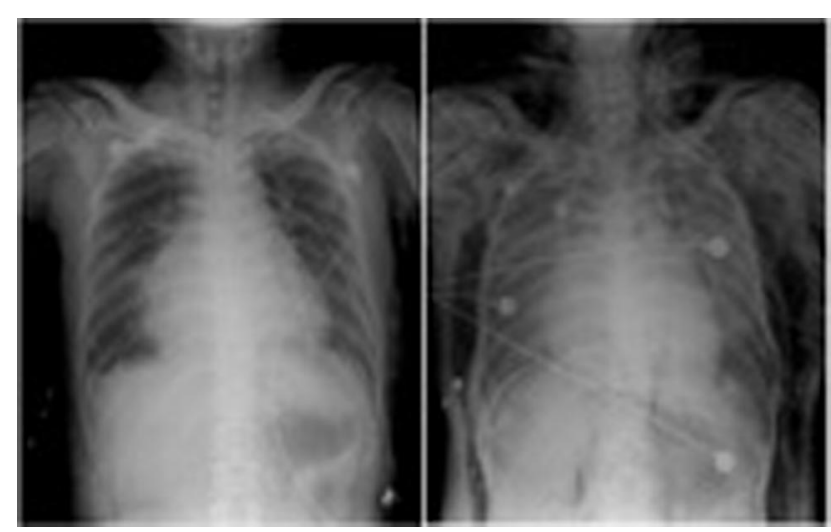

Fig. 1. Left: Chest radiograph shows cardiomegaly and pulmonary congestion. Right: Post-intubation radiograph shows severe subcutaneous emphysema and pneumomediastinum.

revealed cardiomegaly and pulmonary congestion. An arterial blood gas sample while she was on supplemental oxygen via non-rebreathing mask revealed $\mathrm{pH} 7.15, \mathrm{P}_{\mathrm{aO}_{2}} 59 \mathrm{~mm} \mathrm{Hg}$, $\mathrm{P}_{\mathrm{aCO}} 66 \mathrm{~mm} \mathrm{Hg}$, bicarbonate $22 \mathrm{mEq} / \mathrm{L}$, and oxygen saturation $86 \%$. A junior medical resident intubated the patient, with a direct laryngoscope and a 7.5-mm endotracheal tube (ETT) with stylet. Subcutaneous emphysema and pneumomediastinum were suspected soon after intubation, and confirmed via computed tomogram (Fig. 2). Bronchoscopy showed diffuse oozing in the lower trachea. The oozing subsided after local administration of epinephrine. We also found a 5-cm laceration in the membranous part of the trachea, $1 \mathrm{~cm}$ above the carina (Fig. 3). We recommended surgical intervention, but the family chose conservative management because the patient had multiple comorbidities. Therefore, un- 


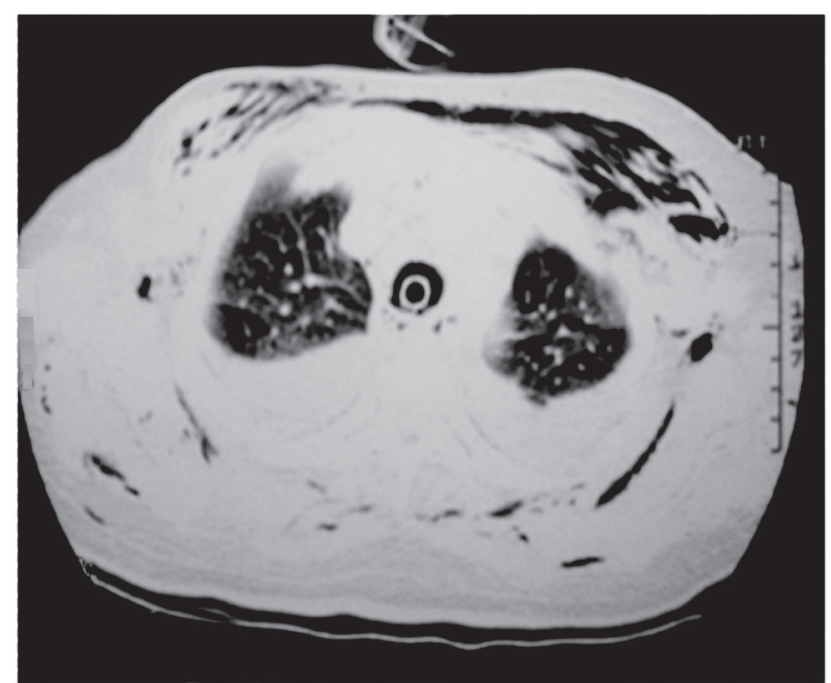

Fig. 2. Computed tomogram shows severe subcutaneous emphysema in the chest wall and back, and pneumomediastinum.

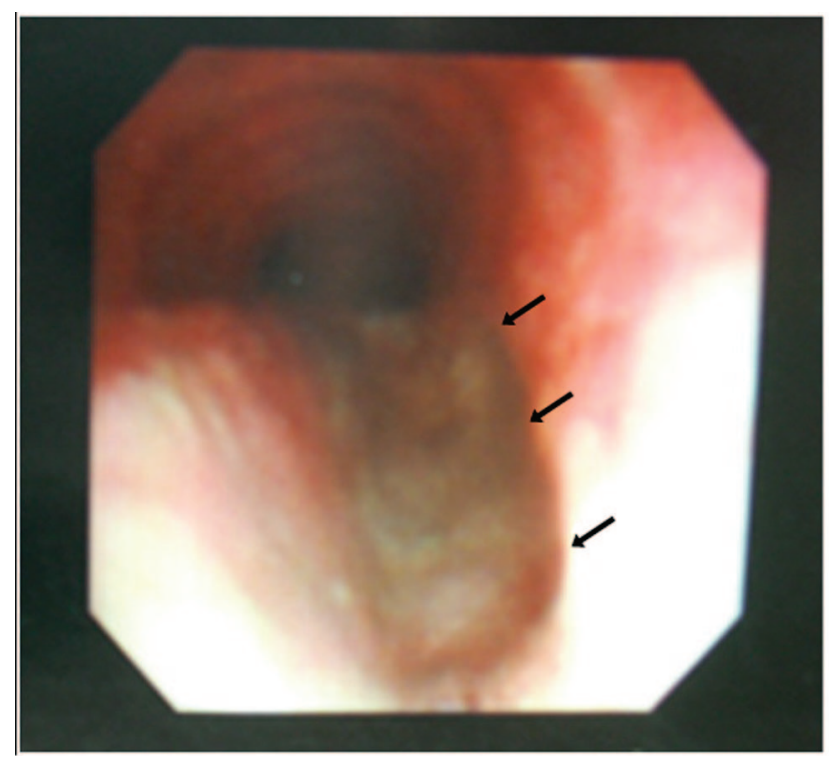

Fig. 3. Bronchoscopy shows a 5-cm laceration in the membranous portion of the trachea, $1 \mathrm{~cm}$ above the carina (arrow).

der bronchoscopic guidance, we adjusted the ETT position so the cuff was proximal to the tracheal tear. We also adjusted the mechanical ventilation settings to lower airway pressure and PEEP. We administered empiric antibiotics (ampicillin plus sulbactam) for 10 days to minimize infection risk. The air leakage decreased gradually over 10 days, and she was successfully weaned from the ventilator one month after admission.

\section{Discussion}

Iatrogenic tracheobronchial injury occurs in approximately 1 of every 20,000 orotracheal intubations. Retrospective anal- ysis revealed an incidence of $15 \%$ in emergency intubations. ${ }^{1}$ Risk factors for intubation airway injury include emergency intubation, inappropriate use of the stylet, incorrect ETT diameter, tracheal-anatomy abnormalities, and excessive inflation of the cuff. Injuries commonly occur in the posterior membranous part of the trachea, most often because of too large an ETT. Intubation injuries are more common in women than in men, probably women have a shorter average tracheal length. ${ }^{2}$ Early bronchoscopy is essential to confirm the diagnosis and to assess the injury. Broad-spectrum antibiotics that are effective against the diverse bacterial population in the tracheobronchial tree should be administered for at least one week. ${ }^{3}$ Lacerations larger than $2 \mathrm{~cm}$ that are accompanied by extensive subcutaneous emphysema and/or respiratory distress are best treated with early surgical repair, if feasible. However, tracheal intubation and inflation of the cuff distal to the tear may be equally effective and may avoid further damage. ${ }^{4}$ In our patient the laceration was very close to the carina, which made it impossible for the cuff to be inflated distal to the laceration. Instead, we placed the cuff proximal to the laceration. This approach, combined with low-pressure mechanical ventilation, was successful. Conservative management is recommended for patients who do not have rapidly progressing subcutaneous or mediastinal emphysema or mediastinitis. ${ }^{5,6}$ In our patient the injury was probably due to the use of a stiff ETT or an inappropriately positioned stylet. The laceration was approximately $5 \mathrm{~cm}$ and complicated by subcutaneous emphysema. From this and other reported cases we conclude that surgical repair is the best option for these patients, but patients with multiple comorbidities usually have an extremely high risk in surgery.

The treatment of intubation-related tracheal laceration is based on the patient's condition. Early surgical repair is preferred for patients with large lacerations, but conservative therapy may be viable in patients with major medical problems.

\section{REFERENCES}

1. Maxeiner H. Weichteilverletzungen an kehlkopf bei notfallmaessiger intubation. Anaesth Intensive Med 1988;29:42-49. Article in German.

2. Hofmann HS, Rettig G, Radke J, Neef H, Silber RE. Iatrogenic ruptures of the tracheobronchial tree. Eur J Cardiothorac Surg 2002; 21(4):649-652.

3. Ross HM, Grant FJ, Wilson RS, Burt ME. Nonoperative management of tracheal laceration during endotracheal intubation. Ann Thorac Surg 1997;63(1):240-242.

4. Marquette $\mathrm{CH}$, Bocquillon N, Roumilhac D, Nevière R, Mathieu D, Ramon P. Conservative treatment of tracheal rupture. J Thorac Cardiovasc Surg 1999;117(2):399-401.

5. Gómez-Caro Andrés A, Moradiellos Díez FJ, Ausín Herrero P, DíazHellín Gude V, Larrú Cabrero E, de Miguel Porch E, Martín De Nicolás JL. Successful conservative management in iatrogenic tracheobronchial injury. Ann Thorac Surg 2005;79(6):1872-1878.

6. Jougon J, Ballester M, Choukroun E, Dubrez J, Reboul G, Velly JF. Conservative treatment for postintubation tracheobronchial rupture. Ann Thorac Surg 2000;69(1):216-220. 